\title{
FEMINIMISME RADIKAL DAN EKSPLOITASI PEREMPUAN SURIAH SEBAGAI OBJEK SEKSUAL TERKAIT IMBALAN BANTUAN KEMANUSIAAN
}

\section{Gulia Ichikaya Mitzy dan Silfanny Zahirah}

Universitas Nasional (UNAS) Jakarta Jawa Barat, Indonesia

Email: guliaichikayamitzy@ civitas.unas.ac.id dan silfannyzhrh@gmail.com

\section{Abstract}

This study aims to explore the level of complexity of humanitarian issues including gender-based violence which raises new agendas in dealing with international conflicts. This research method uses desk-research, which is research whose data sources are obtained from the results of other relevant research and then processed through gap analysis items. The results show that nearly $80 \%$ of the one million Syrian refugees in Lebanon are women and girls. They live jostled in modest houses, garages, tents or precast buildings in cities in Lebanon. Sexual exploitation and violence are common, especially against women. Exploitation of women means the use of everything attached to women, both images and signs attached to them, including as bartering for refugee foodstuffs. Where gender-based sexual violence can damage both physical and mental health, dignity, security and autonomy of its victims, it remains shrouded in a culture of silence. Various kinds of factors underlie how this gender-based violence can occur, one of which is about the abuse of power of a person or a group where this is a criticism of the theory of radical feminism. This abuse of power also occurs in Syria where the practice of sexual exploitation occurs in Syrian women just to get humanitarian assistance.

Keywords: Radical feminism; Women; Sexual-violence; Power, Exploitation

\section{Abstrak}

Penelitian ini bertujuan untuk mengeksplorasi tingkat kompleksitas isu-isu kemanusiaan mencakup kekerasan berbasis gender yang memunculkan agendaagenda baru dalam menghadapi konflik dunia internasional. Metode penelitian ini menggunakan desk-research yaitu riset yang sumber datanya diperoleh dari hasil penelitian lain yang relevan kemudian diolah melalui gap item-item analisis. Hasil penelitian menunjukkan bahwa ampir $80 \%$ dari satu juta pengungsi Suriah di Lebanon adalah perempuan dan anak perempuan. Mereka tinggal berdesakdesakan di rumah sederhana, garasi, tenda atau bangunan asal jadi di kota-kota di Lebanon. Eksploitasi dan kekerasan seksual menjadi umum terjadi terutama terhadap perempuan. Eksploitasi pada perempuan berarti pemanfaatkan segala hal yang melekat pada perempuan, baik citra maupun tanda yang melekat kepadanya termasuk sebagai barter bahan makanan pengungsi. Di mana kekerasan seksual berbasis gender dapat merusak kesehatan baik fisik dan mental, martabat, keamanan dan otonomi para korbannya, namun tetap terselubung dalam budaya 
diam. Berbagai macam faktor mendasari tentang bagaimana kekerasan berbasis gender ini dapat terjadi, salah satunya yaitu tentang penyalahgunaan kekuasaan seseorang atau suatu kelompok dimana hal ini menjadi kritik dari teori feminisme radikal. Penyalahgunaan kekuasaan ini juga terjadi di Suriah dimana praktek eksploitasi seksual terjadi pada perempuan Suriah hanya demi mendapatkan bantuan kemanusiaan.

Kata kunci: Feminisme Radikal; Perempuan; Kekerasan Seksual; Kekuasaan; Eksploitasi

\section{Pendahuluan}

Studi Hubungan Internasional kontemporer dewasa ini berkembang dengan sangat pesat dan dinilai sebagai akibat dari perubahan dramatis yang terjadi dalam praktik hubungan internasional. Perubahan yang ditandai dengan munculnya isu-isu baru, seperti: kemiskinan, global-warming, kerusakan lingkungan, food security, kesetaraan gender, human security dan sebagainya. Perubahan tersebut semakin kompleks dengan hadirnya sejumlah aktor-aktor baru dalam hubungan internasional seperti MNCs, NGOs, kelompok etnik dan global social movement yang kian hari perannya semakin signifikan dalam dunia internasional. Salah satu isu yang menarik perhatian dunia internasional yaitu mengenai kekerasan berbasis gender. Kekerasan berbasis gender yang paling umum terjadi adalah kekerasan terhadap perempuan dan anak perempuan (Human Rights Council, 2018), meskipun tidak menampik bahwa banyak pula kekerasan yang dilakukan terhadap laki-laki.

Kekerasan berbasis gender merupakan salah satu pelanggaran hak asasi manusia yang paling umum di dunia dimana hal ini tidak mengenal batas sosial, ekonomi atau nasional. Menurut laporan tahunan PBB, di seluruh dunia diperkirakan satu dari tiga perempuan akan mengalami pelecehan fisik atau seksual dalam hidupnya (Human Rights Council, 2018). Hal ini juga terjadi pada perempuan-perempuan di Suriah. Kekerasan terhadap perempuan dinilai sangat umum terjadi khususnya pelecehan verbal, kekerasan dalam rumah tangga dan pernikahan muda untuk anak perempuan dibawah umur. Isu ini semakin keras disuarakan mengingat krisis kemanusiaan di Suriah yang berlarut-larut terjadi disebabkan oleh dampak dari Perang Suriah. Kekerasan berbasis gender ini memiliki konsekuensi untuk menghancurkan masa depan perempuan dan anak perempuan Suriah. Mereka menghadapi beban terberat dari krisis Suriah karena keadaan seperti ini terus mengganggu kehidupan hingga mereka tidak merasa aman.

UNFPA mengecam bahwa sejumlah besar perempuan dan anak perempuan Suriah dieksploitasi secara seksual oleh anggota tim yang bertanggung jawab menyediakan bantuan kemanusiaan di daerah konflik tempat tinggal sementara mereka atau biasa disebut kamp. Anggota tim tersebut menyimpan pasokan yang dikirim ke kamp dan menukarnya dengan bantuan seksual. Perempuan Suriah tidak hanya mengalami tindak kekerasan konflik, tetapi mereka juga menjadi korban kekerasan gender, kekerasan seksual, dan kekerasan dalam rumah tangga. Kasus-kasus eksploitasi 
seksual ini sebagian besar dilakukan oleh penyedia lokal yang disewa untuk memberikan bantuan kemanusiaan ke wilayah konflik terbesar di Suriah. Tidak saja terjadi di dunia internasional, beberapa hasil penelitian menunjukkan bahwa eksploitasi terhadap perempuan kini hadir dalam wajah baru, melalui media massa (Haryanto \& Wahyudin, 2017; Syafrini, 2014).

Media masa saat ini memiliki peran ganda, ibarat dua sisi mata uang yang berbeda, disatu sisi media berfungsi sebagai mediator untuk pencerdasan dan kemajuan bangsa namun disisi lain media juga berperan untuk penindasan demikeuntungan dan mulusnya jalan kapitalisme pasar menuju budaya konsumen yang ingin diwujudkan, dan lagi-lagi perempuan yang menjadi sasaran dengan rekayasa pencitraan yang mereka ciptakan (Syafrini, 2014). Karakter media massa seperti ini memunculkan pertanyaan besar dalam konteks sosial-masyarakat, bahkan kemudian membentuk kesimpulan bahwa ternyata perempuan identik dengan perilaku yang negatif yang menjadi sumber eksploitasi kekerasan gender (Hamdani, 2017). Hasil penelitian ini dapat membantu dan memberikan interpretasi dalam menjabarkan kemelut gender terhadap eksploitasi perempuan yang seyogyanya memberi pendidikan yang baik justru menjadi bagian penindasan terstruktur bagi perempuan.

\section{Metode Penelitian}

Metode penelitian yang digunakan adalah kualitatif deskriptif yang merupakan suatu prosedur penelitian yang menghasilkan data deskriptif berupa kata-kata tertulis. Penelitian kualitatif bertumpu pada latar belakang alamiah secara holistik, memposisikan peneliti sebagai alat penelitian yang melakukan analisis data secara induktif dan lebih mementingkan proses daripada hasil penelitian yang dilakukan disepakati oleh peneliti dan subjek penelitian (Sugiyono, 2014). Metode deskriptif dipilih karena metode deskrptif merupakan satu metode dalam meneliti status kelompok manusia, suatu subjek, suatu set kondisi, suatu sistem pemikiran ataupun kelas peristiwa. Adapun tujuan dari penelitian deskriptif ini ialah membuat deskripsi, gambaran atau lukisan secara sistematis serta hubungan antar fenomena yang akan dianalisis.

\section{Hasil dan Pembahasan}

Sebelum konflik Suriah dimulai, banyak warga Suriah yang mengeluh tentang tingkat pengangguran yang tinggi, korupsi dan kurangnya kebebasan politik di bawah pemerintahan Presiden Bashar al-Assad. Presiden Assad menggantikan ayahnya, Hafez, setelah dia meninggal pada tahun 2000. Warga Suriah memiliki harapan besar bahwa Assad yang pada saat itu dinilai cukup muda akan mereformasi sistem yang berlaku. Namun, hal ini ternyata tidak sesuai dengan harapan warga Suriah. Dalam beberapa tahun Assad memang melakukan reformasi dimana "meliberalisasi" ekonomi dengan menjual beberapa perusahaan negara. Assad mengizinkan para pebisnis untuk mendirikan perusahaan seperti perusahaan telepon seluler yang dulunya adalah milik negara. Assad dengan cerdik meningkatkan harapan kekuatan Barat bahwa pebisnis 
mereka bisa mendapatkan keuntungan dari privatisasi. Tetapi hal ini mengacu kepada privatisasi yang lebih menguntungkan keluarga Assad sendiri (Nassif, 2015).

Selain itu, empat tahun kekeringan dahsyat yang dimulai pada tahun 2006 menyebabkan setidaknya 800.000 petani kehilangan seluruh mata pencaharian mereka dan sekitar 200.000 meninggalkan tanah mereka begitu saja (Nassif, 2015). Bahkan di beberapa daerah semua pertanian berhenti. Dilansir dari media New York Times pada tahun 2010, kegagalan panen mencapai 75 persen dan umumnya sebanyak 85 persen ternak mati karena kehausan atau kelaparan. Ratusan ribu petani Suriah meninggalkan pertanian mereka dan melarikan diri ke kota-kota besar dan kecil untuk mencari pekerjaan yang hampir tidak ada dan persediaan makanan yang sangat sedikit. Pengamat luar termasuk para ahli PBB memperkirakan bahwa antara 2 dan 3 juta dari 10 juta penduduk pedesaan Suriah mengalami kemiskinan ekstrem.

Dikarenakan krisis negara yang semakin parah, pada Maret 2011, warga Suriah melakukan aksi demonstrasi damai pro-demokrasi terinspirasi oleh "Arab Spring” di negara-negara tetangga. Aksi damai ini ditanggapi oleh Assad dengan menggunakan kekerasan dan sejata sehingga terjadi kerusuhan. Kerusuhan ini memicu protes nasional yang menuntut pengunduran diri Presiden Assad. Penggunaan kekuatan pemerintah untuk menghancurkan perbedaan pendapat hanya mengeraskan tekad para protestan. Protestan menuntut pengunduran diri Presiden Assad, sementara itu kerusuhan terus menyebar dan penumpasan semakin meningkat. Pendukung oposisi mengangkat senjata, pertama untuk membela diri dan kemudian untuk membersihkan daerah pasukan keamanan mereka. Hal inilah yang memicu terjadinya perang sipil Suriah yang tidak kunjung usai hingga mengakibatkan banyak pihak asing yang ikut campur dan memiliki tujuannya sendiri.

Menurut data yang dilansir oleh (BBC, 2018), dampak dari perang tersebut mengakibatkan 6,5 juta orang secara internal mengungsi di Suriah, 1,2 juta diusir dari rumah mereka pada tahun 2015. PBB menyebutkan bahwa butuh setidaknya $\$ 3,2$ milyar untuk membantu 13,5 juta orang, termasuk 6 juta anak-anak yang akan memerlukan beberapa bentuk bantuan kemanusiaan di dalam wilayah Suriah pada 2016. Sekitar 70\% populasi tidak memiliki akses ke air minum yang memadai, satu dari tiga orang tidak dapat memenuhi kebutuhan makanan pokok mereka, dan lebih dari 2 juta anak tidak bersekolah, dan empat dari lima orang hidup dalam kemiskinan (Council, 2016). Pihak-pihak yang bertikai telah memperparah masalah dengan menolak akses lembaga kemanusiaan kepada warga sipil yang membutuhkan.

Krisis internal yang semakin parah kemudian berdampak cukup signifikan terhadap kaum perempuan. Kaum perempuan yang mayoritas hidup dalam lingkungan domestik menjadi terabaikan. Sehingga, memunculkan kasus-kasus berbasis gender terhadap perempuan maupun anak-anak. Konstruksi sosial masyarakat yang patriarki juga semakin mendukung adanya kekerasan tersebut.

\section{A. Eksploitasi Perempuan di Suriah}

Kekerasan seksual dan berbasis gender terutama terhadap perempuan dan anak perempuan telah menjadi masalah yang terus-menerus terjadi di Suriah sejak 
awal pemberontakan bermula. Kekerasan seksual dijadikan sebagai alat untuk menanamkan rasa takut, menghina dan menghukum atau sebagai bagian dari ketertiban sosial. Kekerasan seksual ini dilakukan oleh kelompok utusan pemerintah atau milisi dengan melakukan pemerkosaan dan pelecehan seksual terhadap perempuan dan anak perempuan selama operasi darat, penggerebekan rumah untuk menangkap pengunjuk rasa dan yang dianggap pendukung oposisi, dan di pos pemeriksaan (European Asylum Support Office (EASO), 2020) Para pelaku menggunakan kekuasaan mereka untuk memaksa pengakuan, mengekstraksi informasi, sebagai hukuman, serta meneror komunitas oposisi. Pemerkosaan dan tindakan kekerasan seksual lainnya yang dilakukan oleh kelompok utusan pemerintah atau milisi terjadi selama operasi darat, penggerebekan rumah, di pos pemeriksaan dan selama penahanan merupakan bagian dari serangan yang meluas dan sistematis yang ditujukan terhadap penduduk sipil.

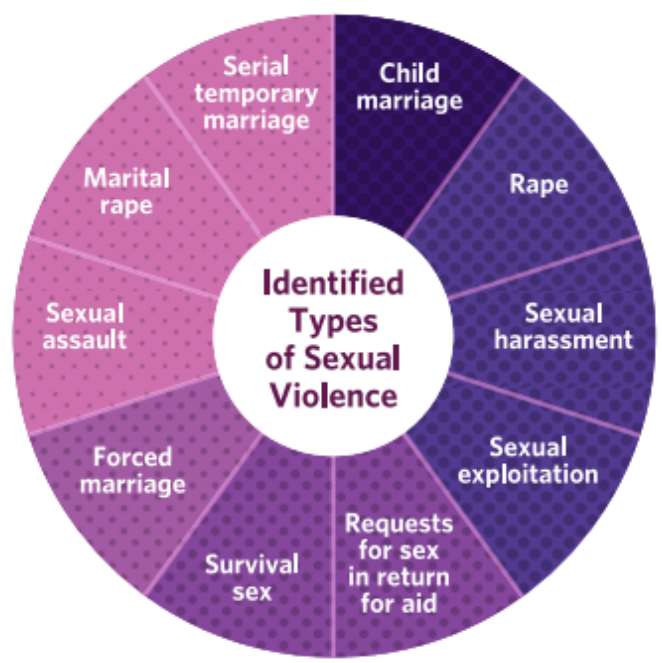

Grafik 1

Jenis-Jenis Kekerasan Seksual (UNFPA, Voices From Syria 2018, 2018)

Kekerasan dalam rumah tangga merupakan salah satu jenis kekerasan berbasis gender yang paling umum disebutkan yang mempengaruhi perempuan (Alifa, 2013). Pernikahan anak dan kekerasan dalam rumah tangga bukanlah isu baru di Suriah dimana hal ini sering dinormalisasi dan tertanam dalam budaya mereka. Namun peningkatan kekerasan dalam rumah tangga sejak awal krisis yang telah membawa perubahan dalam dinamika keluarga dengan perempuan yang bekerja di luar rumah untuk berkontribusi atau menjadi penyedia tunggal pendapatan keluarga. Beberapa perubahan yang keluarga hadapi karena krisis bersifat struktural, seperti kemiskinan, kenaikan harga, pengangguran, dan pemindahan, sementara yang lain bersifat psikologis juga tekanan-tekanannya. Baik laki-laki maupun perempuan mendiskusikan bagaimana korban yang berkelanjutan dari masalah-masalah ini pada peran kekuasaan tradisional telah mengikis kapasitas laki-laki untuk 
mengelola kemarahan mereka. Tekanan yang mereka rasakan telah menurunkan ambang batas di mana mereka melakukan kekerasan.

Sekitar satu setengah juta orang tinggal di kota terbesar kedua di Suriah tersebut sebelum krisis terjadi. Setelah perang terjadi, hanya sekitar 100 ribu hingga 300 ribu orang yang tersisa. Dampak dari perang ini sangat berpengaruh terhadap perempuan Suriah karena banyak dari mereka yang kehilangan ayah maupun suami mereka. Dua dari setiap lima keluarga, perempuan berperan sebagai satu-satunya pencari nafkah. Para perempuan ini tidak memiliki tempat kerja atau sumber pendapatan selain bantuan yang mereka terima dari kelompok bantuan internasional. Sebagian besar keluarga tidak memiliki listrik atau air bersih, dan harus membeli listrik dengan biaya tinggi dari pemilik generator, dan air galon dari penjual air. Beberapa keluarga cukup beruntung karena mereka memiliki anggota keluarga yang bertugas di militer Suriah dan mereka menerima beberapa gaji.

Sementara itu kondisi para ibu tunggal lebih baik bila dibandingkan dengan perempuan yang harus menjual tubuhnya untuk mendapatkan bantuan dari kelompok amal. Bantuan didistribusikan oleh para pekerja lokal, yang memanfaatkan posisi mereka untuk mendapatkan kesenangan seksual dengan imbalan makanan. Seorang perempuan mengatakan bahwa seorang petugas organisasi tersebut mengusulkan pernikahan sementara kepadanya sebagai imbalan atas janji persediaan makanan yang terus berlanjut (Martínez \& Eng, 2016). Ketika ia menolak, petugas tersebut mengatakan kepadanya bahwa ia tidak akan lagi menerima bantuan. Berdasarkan sumber yang sama perempuan lain disebutkan bahwa mereka menghindari pusat distribusi karena takut akan pelecehan, penghinaan bahkan pemerkosaan. Hubungan antara makanan dan seks telah menjadi sangat umum, sehingga perempuan tidak pergi ke pusat distribusi karena takut tetangga mereka memandang mereka sebagai pelacur.

Sebuah laporan penelitian yang diterbitkan oleh Relief Web atau Pusat Krisis dan Bencana Global PBB yang berjudul "Suara dari Suriah 2018" menyebutkan sejumlah data dan kesaksian mengenai kekerasan, pelecehan, dan serangan seksual terhadap perempuan dewasa, remaja perempuan, dan gadis-gadis muda di instalasi dan kamp pengungsian rezim tersebut. Kamp ini merupakan tempat yang paling tidak aman bagi perempuan Suriah. Bantuan jarang diterima secara gratis, sebagian besar bantuan tersebut didistribusikan dengan imbalan uang atau dengan imbalan layanan seksual untuk menerima makanan. Tetapi banyak perempuan tidak melaporkan hal ini karena ketergantungan mereka pada paket bantuan dan untuk menghindari rasa malu (UNFPA, 2019).

Hambatan sosial pergerakan bagi perempuan dan anak perempuan merupakan sebuah masalah keamanan seperti penculikan dan kekerasan seksual, perempuan dan anak perempuan juga menyatakan keprihatinan yang sama tentang stigma dan kerusakan pada reputasi mereka yang mereka hadapi oleh keluarga dan masyarakat jika mereka ke luar rumah (Alifa, 2013). Perempuan di Suriah telah menghadapi beberapa pembatasan gerakan sebelum krisis karena tradisi dan norma budaya yang 
menekankan kehormatan perempuan, banyak perempuan dan anak perempuan menarik perhatian pada perbedaan yang mencolok antara kebebasan bergerak mereka sebelum dan sesudah krisis untuk budaya, bukan keselamatan misal seperti pentingnya menghindari skandal dan gosip. Di beberapa daerah, kelompok ekstremis memberlakukan aturan yang lebih ketat untuk perempuan dan anak perempuan dibandingkan sebelum krisis (Cook, 2016).

Perempuan yang bercerai dan perempuan sebagai orangtua tunggal dianggap memiliki risiko khusus terhadap kekerasan seksual, emosional dan pelecehan verbal. Pernikahan paksa, poligami dan pernikahan sementara, pembatasan gerakan, kekerasan ekonomi dan eksploitasi juga termasuk di dalamnya. Para janda dan perempuan yang bercerai merasa takut anak-anak mereka akan diambil atau dibawa paksa bahkan dipisahkan dengan anak-anak mereka untuk dipekerjakan. Alasan mengapa anak-anak itu akan dipisahkan atau ditinggalkan di masyarakat, kematian pengasuh itu paling sering disebutkan dan diikuti oleh pernikahan kembali orang tua, khususnya ibu dan perceraian ketiga (Cook, 2016). Kekurangan atau hilangnya dokumentasi sipil atau dokumen terkait properti juga memiliki implikasi besar bagi para janda yang dipisahkan atau perempuan yang sudah bercerai.

Dilansir oleh media BBC pada tahun 2018, pelecehan seksual dan eksploitasi seksual terjadi dalam konteks distribusi secara signifikan. Adanya oknum-oknum yang mengatasnamakan PBB yang ingin memberikan bantuan dengan menukar fasilitas yang berupa makanan dan kebutuhan rumah tangga dengan "kepuasan seksual" yang tentunya disanggupi oleh mereka agar dapat bertahan hidup. Paksaan seperti ini termasuk ke dalam pelecehan seksual berat dan melanggar hak-hak kemanusiaan. Perempuan hanya bisa pergi untuk distribusi dengan pendamping, kebanyakan remaja perempuan terhalang untuk pergi ke situs distribusi karena kurangnya pendamping laki-laki. Beberapa perempuan pergi ke pusat distribusi bantuan dengan saudara laki-laki atau saudara mereka dan kadang-kadang mengirim seseorang untuk menerima bantuan. Beberapa perempuan menolak pergi ke pusat bantuan dan menerima bantuan karena takut akan pelecehan, dan beberapa perempuan berhenti menerima bantuan karena perlakuan provokatif yang mereka terima dari distributor.

Sebagai contoh seorang gubernur di Suriah, perempuan atau anak perempuan dinikahkan sementara dengan jangka waktu yang singkat dengan pejabat untuk layanan seksual hanya demi menerima makanan. Distributor meminta nomor telepon perempuan atau anak perempuan tersebut, memberi mereka tumpangan ke rumah mereka kemudian mengambil sesuatu sebagai imbalan (Kompas, n.d.). Ada pula perempuan yang diperas oleh distributor dengan kedok meminta bantuan dari perempuan dengan imbalan layanan untuk memperoleh distribusi dalam pertukaran untuk kunjungan ke rumahnya atau dalam pertukaran layanan seperti dipaksa untuk "menemani" para distributor tersebut. Perempuan tanpa pelindung laki-laki, seorang janda dan perempuan yang telah bercerai,s serta para pengungsi perempuan dianggap sangat rentan terhadap eksploitasi seksual. 
Dikarenakan fenomena tersebut, maka penulis menggunakan Teori Feminis Radikal dalam membentu menganalisa masalah. Teori feminis radikal hadir untuk mengkritik dan menuntut akan kesetaraan gender (Andestend, 2020). Yang dimaksud kesetaraan gender disini bukan berarti menuntut persamaan atas atanomi biologis, gender menjelaskan kepentingan atau pengertian sosial yang ditujukan terhadap perbedaan-perbedaan itu. Teori Feminis Radikal memandang bahwa isu kesetaraan gender ini terjadi karena adanya ketimpangan struktur sosial yang berkesinambungan dengan tujuan politis negara. Dalam hal ini negara sudah gagal dalam melindungi warga negaranya sendiri dan tidak dapat memberikan rasa aman yang seharusnya itu sudah menjadi hak tiap individu warga negara.

Dalam hal ini, Negara Suriah memiliki rancangan dan penegakan hukum yang buruk untuk kekerasan terhadap perempuan. Bahkan kebanyakan dari mereka adalah politisi yang menggunakan perempuan hanya untuk kepuasan mereka saja. Sangat jelas bahwa disini perempuan bukan hanya diabaikan hak-haknya sebagai perempuan tetapi juga melanggar hak-hak sebagai individu dan anggota negara.

Negara Suriah juga memiliki budaya patriarki yang sangat kental, pemerintah maupun pejabat setempat dianggap tidak bisa mengakomodir hak-hak kaum perempuan. Hal ini termasuk ke dalam kritik teori feminis radikal terhadap teori tradisional dimana power menjadi senjata utama yang mengatasnamakan segalanya termasuk merusak dan tidak memandang hak-hak kemanusiaan. Power disini dimaksudkan dengan kapabilitas pemerintah dalam mengintervensi rakyatnya dalam hal ini berkenaan dengan isu kemanusiaan.

Munculnya intervensi kemanusiaan dan bantuan kemanusiaan dalam praktekpraktek Hubungan Internasional menjadi bukti bahwa ada masalah-masalah kemanusiaan yang muncul bersamaan dengan pendekatan negara dalam penyelesaian konflik dan penanggulangan bencana yang terjadi dalam suatu negara. Isu ini sudah diangkat ke tingkat atau kancah internasional mengingat Konflik Suriah sudah banyak campur tangan internasional. PBB juga mengangkat kasus ini karena laporan tak henti yang kunjung diadukan kepada lembaga tersebut. Dus, isu mengenai kekerasan berbasis gender di Suriah ini harus mendapatkan perhatian penting, mengingat konflik yang masih berlangsung dan dikhawatirkan akan menambahkan kasus berbasis gender lainnya.

\section{Kesimpulan}

Perspektif feminisme telah membantu menyuarakan agenda atau isu yang selama ini terpendam atau tidak diperhatikan oleh pendekatan-pendekatan tradisional atau klasik dengan metode berpikir yang positivis. Konflik tidak lagi dilihat dari masalah perang terbuka antar negara dengan aktor negara dan kekuatan militernya. Jangkauan konflik meluas ke arah yang lebih luas seperti konflik etnis, agama dan sosial yang terjadi dalam suatu negara atau ketegangan batas wilayah antar negara. Selain itu, konflik tidak lagi dilihat dari sudut pandang negara saja tetapi meluas kepada masalah kemanusian. 
Kekerasan berbasis gender, khususnya pelecehan verbal, kekerasan dalam rumah tangga, pernikahan anak-anak dan ketakutan akan kekerasan seksual terus berkembang. Kasus Suriah merupakan isu penting yang patut untuk mendapat perhatian khusus dalam dunia internasional mengingat bagaimana Negara Suriah mengabaikan hak-hak perempuan bahkan dimanfaatkan oleh pejabat-pejabat negara itu sendiri dan juga mengabaikan hak-hak perempuan sebagai manusia. Kasus Suriah adalah salah satu dari banyak kasus mengenai pelecehan perempuan di dunia ini. Hak-hak perempuan harus diperjuangkan agar tidak ada lagi ketidakadilan yang dirasakan oleh kaum perempuan. 


\section{BIBLIOGRAFI}

Alifa, Nurvina. (2013). Antara Perlindungan dan Pembatasan: Seksualitas dan Perempuan dalam Pandangan KPI. Jakarta: Remotivi

Andestend, Andestend. (2020). Feminisme Sosialis Di Dalam Novel Mencari Perempuan Yang Hilang Karya Imad Zaki. Jurnal Ilmiah Korpus, 4(2), 138-147.

BBC. (2018). Konflik Suriah: Perempuan 'dieksploitasi secara seksual dengan imbalan bantuan kemanusiaan. Retrieved from https://www.bbc.com/indonesia/dunia43207848 diakses pada 20 Juni 2020

Cook, Sam. (2016). The 'woman-in-conflict'at the UN Security Council: a subject of practice. International Affairs, 92(2), 353-372.

Council, Human Rights. (2016). Women's International League for Peace and Freedom. Violations against women in Syria and the disproportionate impact of the conflict on them. Universal Periodic Review of the Syrian Arab Republic.

European Asylum Support Office (EASO). (2020). Easo Country Of Origin Report: Syria-The Situation Of Women. https://doi.org/doi: 10.2847/419604

Hamdani, Ahmad. (2017). Eksploitasi Perempuan Di Media Massa Perspektif Alquran. Jurnal Harkat: Media Komunikasi Gender, 13(1), 104-115.

Haryanto, Tri, \& Wahyudin, Didin. (2017). Eksploitasi Perempuan Dalam Media Massa Dan Tinjauan Islam. Martabat: Jurnal Perempuan Dan Anak, 1(2), 279-300.

Human Rights Council. (2018). "I lost my dignity": Sexual and gender-based violence in the Syrian Arab Republic. https://reliefweb.int/report/syrian-arab-republic/i-lostmy-dignity-sexual-and-gender-based-violence-syrian-arab-republic

Kompas. (n.d.). Demi Bantuan, Perempuan Suriah Dieksploitasi secara Seksual. https://internasional.kompas.com/read/2018/02/27/15594551/demibantuanperempuan-suriah-dieksploitasi-secara-seksual?page=all diakses pada 25 Juni 2020.

Martínez, José Ciro, \& Eng, Brent. (2016). The unintended consequences of emergency food aid: neutrality, sovereignty and politics in the Syrian civil war, 2012-15. International Affairs, 92(1), 153-173.

Nassif, Hicham Bou. (2015). Inside Syria: The Backstory of Their Civil War and What the World Can Expect. Political Science Quarterly, 130(4), 771-774.

Sugiyono. (2014). Metode Penelitian Kuantitatif Kualitatif Dan R\&D (12th, Cetaka ed.). Bandung: CV Alfabeta.

Syafrini, Delmira. (2014). Perempuan dalam Jeratan Eksploitasi Media Massa. 
Gulia Ichikaya Mitzy dan Silfanny Zahirah

Humanus, 13(1), 20-27.

UNFPA. (2019). Voices From Syria 2nd Edition. Retrieved from https://reliefweb.int/sites/reliefweb.int/files/resources/voices_from_syria_2019.pdf diakses pada 9 Agustus 2020 